\title{
The Analysis of Development Condition of Taekwondo Dan System in Hebei Province
}

\author{
Shen Cao and Yuanhui Zhang \\ Shijiazhuang Institute of Technology, 050228 Shijiazhuang Hebei, China
}

\begin{abstract}
This article made use of the literature, questionnaire and mathematical statistics method for the Taekwondo practitioners and coaches in Hebei province to carry out investigation, analysis on the development situation of Dan system of Taekwondo, to influence and implement Dan system development of Taekwondo in Hebei province. The results showed, most road museums are organizing assessment of Dan System, but there is still half of the practitioners are willing to participate in grading system of examination and did not participate in. The results show that the development of grading system of Taekwondo in Hebei province, however, there are still some problems. The research of this paper provides a theoretical basis for the development of Hebei province, but also to contribute to the promotion of Taekwondo Dan made better development in Hebei province.
\end{abstract}

Keywords. Dan system; Taekwondo; development; influence

\section{Introduction}

Taekwondo is a kind combat project of originated in the Korean Peninsula, which is a unique movement form of Korean nationality. Independent development of Taekwondo has a history of more than 2000 years. Taekwondo in the long process of development has formed a perfect system. In 2000, combat taekwondo became an Olympic sport has been accepted by many countries in the world. Taekwondo is literally "kick and boxing. Taekwondo not only emphasizes the body movement, but also with special emphasis on the moral quality and the development of mind, from tae kwon do the effects of exercise, exercise, exercise the self-confidence and culture of human fortitude will. With the development of Taekwondo in the world, showing two different development directions: One is the International Taekwondo Federation advocates with Taekwondo Poomsae walkthrough based, the other is the World Taekwondo Federation advocacy of competitive taekwondo. The writing of this paper focuses on the International Taekwondo Federation, because the development of Taekwondo Dan system mainly based on the masses.

\section{The object and method of research}

\subsection{The object of research}

Take Taekwondo enthusiasts, coaches and curators in the Museum of Hebei province as the research object, using the method of random sampling.

\subsection{The method of research}

1) Questionnaire

180 questionnaires, 50 questionnaires were sent to the trainer, recovery of 50 copies; curator of 30 questionnaires, 30 were recovered, 80 effective questionnaires; the practitioners of 100 questionnaires, recovery of 98 copies, 95 copies of effective questionnaire.

2) Data analysis

The results of the survey were analyzed and concluded.

3) The literature

Dan literature materials collected by domestic academic journals network, library etc.

\section{The analysis of result}

\subsection{Dan system analysis of Taekwondo}

Dan Taekwondo is divided into ten stages and nine sections, including the promotion and Jin period of two parts. Level Title ranged from low to high as level ten, level nine, level eight, level seven, level six, level five, level four, level three, level two, level. Dan ranged from low to high as one section, two section, three section, four section, five section, six section, seven section, eight section, nine section. One to three section for junior grade, four to six section for the intermediate grade, seven to nine section for senior grade. 
The appraisal rules of Chinese Taekwondo Dan system must be declared by each area management department or area Taekwondo Association to the General Administration of sports and Chinese Taekwondo association. If approved for their organization level assessment. There are clear for Dan appraisal institutions appraisal. But the examiner should have higher grade, clear taekwondo black belt six and senior grade, at the same time the evaluation unit is divided into general appraisal committee and senior assessment committee.

\subsection{The analysis on the investigation in Hebei province Taekwondo}

In this paper, 14 family museums, 2 sports schools, 8 university Taekwondo clubs in Hebei Province, Taekwondo Dan system to carry out research.

\subsubsection{Taekwondo practice' understanding of Dan system assessment (see Table 1)}

Table 1. Practitioners' attitude of Taekwondo Dan system.

\begin{tabular}{|c|c|c|}
\hline Options & Yes & No \\
\hline $\begin{array}{l}\text { Whether to participate in the Dan system } \\
\text { assessment }\end{array}$ & $48.33 \%$ & $51.67 \%$ \\
\hline Whether voluntary assessment & $85.32 \%$ & $14.68 \%$ \\
\hline $\begin{array}{l}\text { What do they know about Dan system } \\
\text { assessment }\end{array}$ & $71.33 \%$ & $28.67 \%$ \\
\hline $\begin{array}{l}\text { To participate in the assessment of } \\
\text { whether promoting Taekwondo learning }\end{array}$ & $91.51 \%$ & $8.49 \%$ \\
\hline
\end{tabular}

Result analysis: Dan system development of Taekwondo in Hebei province is not very ideal. $48.33 \%$ trainers participated in Dan system assessment. Of which $14.68 \%$ of the practitioners are not voluntarily. $91.51 \%$ trainers think: participating in the Dan system evaluation can promote the learning of taekwondo. And practitioners' evaluation purpose in Dan system is different. The younger of Taekwondo like test with reason is derived from encourage, enhance self-confidence, a positive participation in exercise success. University club practices think that level and Dan imply different degree of Taekwondo practice, hope to get a higher grade or grade, truly understand the meaning and purpose of Taekwondo Dan system evaluation.

\subsubsection{Taekwondo workers' understanding of the Taekwondo Dan system (see Table 2)}

Results analysis: 56.44\% Museum Road or assessment of sports school organizes Dan system, and each Road Museum is in different scale grade system appraisal, they think Dan system evaluation is an effective means to Hall Road, recruit students, and to actively increase taekwondo practice. Most sports school and university club, no organization Dan system assessment. Sports players in sports competitions, the excellent results achieved as the ultimate goal. The University Taekwondo Club for students spontaneously established, there is no unified organization, unable to organize Dan system assessment.
Table 2. Coaches, curator survey list.

\begin{tabular}{lll}
\hline Options & Yes & No \\
\hline Dan assessment organization & $56.44 \%$ & $43.56 \%$ \\
$\begin{array}{l}\text { Dan system evaluation is conducive to } \\
\text { the development of Taekwondo }\end{array}$ & $83.62 \%$ & $16.38 \%$ \\
$\begin{array}{l}\text { Dan system assessment to take voluntary } \\
\text { According to the provisions of the as- }\end{array}$ & $87.62 \%$ & $2.38 \%$ \\
sessment in Taekwondo Association & & $12.53 \%$ \\
\hline
\end{tabular}

Seen from table 2, 83.62\% of the coaches think Dan Taekwondo evaluation to development of taekwondo, $16.38 \%$ think had no effect on the development of Taekwondo Dan system assessment, this part mostly from sports school. They think Dan's height does not determine athletic performance. At the same time division club coaches think Dan system evaluation will enhance student tuition fees, even if the participants agree, some parents will be opposed or resentful attitude. The results will cause the loss of students. In addition, $12.53 \%$ of taekwondo and sports schools did not follow the way of examination of Taekwondo Association grading system of strict examination.

(1) The majority of Taekwondo and workers in favor of Taekwondo Dan system assessment

(2) Only the strict implementation of appraisal system of Taekwondo Dan system, can be systematic, scientific development.

(3) Dan is the evaluation of Taekwondo students level standards, so that practitioners have exercise standards and goals, what level, stimulate practitioner interest in learning, enhance the enthusiasm of practitioners.

(4) Taekwondo Dan system affects the development of Taekwondo in many ways, it plays an irreplaceable role in the development of Taekwondo step by step, make coaches teaching, teaching content system, standardization, integration, and form a unified system.

\section{Conclusions and recommendations}

\subsection{Conclusions}

Assessment of most Taekwondo organization in Hebei province Taekwondo Dan system is to recruit students, for the purpose of profit, will also have a certain social effect. Therefore, Dan system in the Tao hall to carry out the situation is optimistic

The appraisal situation of Sports schools is worse. The main purpose of sports schools of Taekwondo Teaching is the pursuit of sports performance. With respect to the Tae Kwon Do the teaching of culture is inferior to the Taekwondo hall.

The practices in University Taekwondo club are more for the spontaneous organization of college students, lack of professional guidance, unable to complete the grading system of examination in school. Part of the school attended a professional class of merit system in Taekwondo hall.

\subsection{Recommendations}


Each Taekwondo should conscientiously implement the Taekwondo Dan system developed by Chinese Taekwondo Association, assess strictly in accordance with the time Dan Taekwondo promotion action, and evaluation standard requirements, to promote the rapid development of taekwondo.

\section{References}

1. Rick, G.T. Modern Taekwondo [M]. Beijing: The Modern Publishing House, 2004.

2. Liu, W.J. Taekwondo [M]. Beijing: Beijing Sport University Press, 2000.
3. Liu, Y.J. Enlightenment of development of Taekwondo to China martial arts [J]. Journal of Hunan Institute of Humanities Science and Technology, 2007, 8(4).

4. Li, S. \& Qiao, W. Mass Sports and Fitness (Taekwondo) [M]. Beijing: Military Yiwen Press, 2006.

5. Li, Y. \& Qiao, W. Investigation of Taekwondo Dan made the situation carried out in Hebei Province [J]. Journal of Chifeng University, 2010. 8.

6. Cui, D.L., Chang, J.P. \& Zhao, L. Chinese Public Taekwondo Tutorial [M]. Beijing: People's sports press, 2009. 